\title{
Primary tumorectomy promotes angiogenesis and pulmonary metastasis in osteosarcoma-bearing nude mice ${ }^{1}$
}

\author{
Zhi-Yuan Wang, Jiong Mei" ${ }^{\mathrm{II}}$, You-Shui Gao ${ }^{\mathrm{III}}$, Ming Ni ${ }^{\mathrm{IV}}$, Bin Yaov \\ IDoctor degree, Department of Orthopedic Surgery, Tongji Hospital, Tongji University, Shanghai, China. Main author. Study design and manuscript \\ preparation. \\ IF Full Professor, Department of Orthopedic Surgery, Tongji Hospital, Tongji University, Shanghai, China. Study design and manuscript preparation. \\ IIIDoctor degree, Department of Orthopedic Surgery, Shanghai Sixth People's Hospital, Shanghai Jiao Tong University, Shanghai, China. Critical \\ revision. \\ Iv Doctor degree, Department of Orthopedic Surgery, Tongji Hospital, Tongji University, Shanghai, China. Technical procedures. \\ ${ }^{v}$ Department of Orthopedic Surgery, Tongji Hospital, Tongji University, Shanghai, China. Statistical analysis.
}

\begin{abstract}
PURPOSE: To investigate the effect of primary tumorectomy on angiogenesis and pulmonary metastasis in osteosarcoma-bearing nude mice.

METHODS: Osteosarcoma was introduced to nude mice via subcutaneous injection of MG-63 cells. One hundred and eighty osteosarcoma-bearing mice were used equally in 3 parallel experiments. The effect of tumorectomy (TR) on the expression of vascular endothelial growth factor (VEGF) and endostatin was investigated by ELISA. Meanwhile, the effect on angiogenesis was evaluated by Matrigel plug assay, and pulmonary metastasis assessed by calculating the metastatic foci. Sham-operation (SO) and untreated (UT) groups served as controls.

RESULTS: The VEGF (TR: $79.55 \pm 7.82 \mathrm{pg} / \mathrm{mL} v$. SO: $110.01 \pm 5.69 \mathrm{pg} / \mathrm{mL}$, UT: $123.50 \pm 10.41 \mathrm{pg} / \mathrm{mL} ; p<0.01$ ) and endostatin (TR: $47.09 \pm 6.22 \mathrm{ng} / \mathrm{mL}$ vs. SO: $117.64 \pm 7.39 \mathrm{ng} / \mathrm{mL}$, UT: $126.73 \pm 6.55 \mathrm{ng} / \mathrm{mL} ; p<0.01$ ) were down-regulated significantly after tumorectomy, and angiogenesis was significantly promoted simultaneously. The incidence of pulmonary metastatic foci was $80.0 \%$ in the TR group, $40.0 \%$ in the SO group and $35.0 \%$ in the UT group.

CONCLUSION: Primary tumorectomy can down-regulate the expression of VEGF and endostatin and promote angiogenesis which leads to the acceleration of pulmonary metastasis. These findings imply that anti-angiogenic treatment can be considered after primary tumorectomy.
\end{abstract}

Key words: Osteosarcoma. Neplasm Metastasis. Vascular Endothelial Growth Factor A. Endostatins. Tumor Resistance. Mice. 


\section{Introduction}

Osteosarcoma is a highly malignant tumor occurring frequently in children and young adults ${ }^{1}$. Similar to other solid tumors, osteosarcoma often metastasizes to distant organs, especially the lung in early phase ${ }^{2}$. Generally, the metastatic foci are always very small and may not cause symptoms, which makes the diagnosis difficult and leads to poor response to conventional treatments including surgical intervention and aggressive cytotoxic chemotherapy ${ }^{3,4}$. Pulmonary metastasis is proved to be a major cause of death in patients suffering from osteosarcoma ${ }^{5}$. However, little is known about the exact mechanism underlying the spontaneous pulmonary metastasis of osteosarcoma. Several factors have been found to be associated with osteosarcoma metastasis in which concomitant tumor resistance (CTR) plays an important role ${ }^{6-8}$. The CTR is a phenomenon in which a tumorbearing host is resistant to the growth of secondary tumor implants and metastasis via the systemic angiogenic suppression. After primary tumorectomy, the angiogenesis and pulmonary metastasis might be accelerated ${ }^{9,10}$.

A preliminary report has been published previously in which the relationship between tumorectomy and pulmonary metastasis was investigated ${ }^{11}$. The present study aimed to investigate the effect of primary tumorectomy on angiogenesis and pulmonary metastasis in osteosarcoma-bearing nude mice and to explore the relationship among angiogenesis, pulmonary metastasis and primary tumorectomy. The probable mechanism and implication of CTR was also discussed on the basis of findings in the present study and previous studies.

\section{Methods}

This study was carried out in the Tongji University School of Medicine, Shanghai, China. The study was approved and in accordance with the Animal Welfare Regulations of TUMS. Nude mice (Balb/c, nu/nu) in the present study were purchased from the SLAC Laboratory Animal of Chinese Academy of Science (Shanghai, China). Mice were 5-week-old and had a body weight of $16 \sim 20 \mathrm{~g}$. They were housed in a specific pathogen-free environment at TUMS.

\section{Cell culture}

A human osteosarcoma cell line, MG-63 cells, was purchased from the American Typical Culture Collection (Manassas, VA) and maintained in RPMI-1640 (Gibco; Carlsbad, $\mathrm{CA}$ ) containing $20 \%$ fetal bovine serum (FBS) at $37^{\circ} \mathbf{C}$ in an environment with $5 \% \mathrm{CO}_{2}$. Cells were serially subcultured to $80 \%$ confluence, then digested and harvested for centrifugation at $1500 \mathrm{rpm}$ for $5 \mathrm{~min}$. The supernatant was removed, and the MG63 cells were suspended in RPMI-1640 at a density of $1.0 \times 10^{7}$ cells $/ \mathrm{mL}$. When cell viability was over $90 \%, 0.2 \mathrm{~mL}$ of cell suspension $\left(2.0 \times 10^{6}\right.$ cells $)$ was injected subcutaneously into the left forelimb of nude mice. Two weeks later, 180 cancer-bearing mice were randomly used in three parallel experiments $(n=60$ in each experiment) with three individual groups: tumorectomy (TR at left forelimb amputation) group, sham-operation (SO at right forelimb amputation) and untreated (UT) group.

\section{Sampling and detection}

On days 7, 14 and 21, five mice in each subgroup were anesthetized at each time point and blood $(1.0 \mathrm{~mL})$ was obtained. On day 21, five mice received left forelimb amputation in the TR group and right forelimb amputation in the SO group; and five mice were left untreated in the UT group. On day 28, five mice in five groups were anesthetized and $1.0 \mathrm{~mL}$ of blood was obtained. Plasma was prepared by centrifugation and allowed to keep at room temperature for $1 \mathrm{~h}$. Serum was educed overnight at $4^{\circ} \mathrm{C}$ and centrifuged at $3000 \mathrm{rpm}$ for $10 \mathrm{~min}$. The supernatants were transferred and preserved. Enzyme-linked immunosorbent assay (ELISA) was employed to detect the content of VEGF and endostatin according to the manufacturer's instructions (VEGF kit: Invitrogen, Carlsbad, CA; endostatin kit: R\&D, Minneapolis, $\mathrm{MN})$.

On days 1, 7 and 14, $0.5 \mathrm{~mL}$ of Matrigel (BD; Bedford, MA) containing $200 \mathrm{ng}$ of $\mathrm{bFGF}$ and $50 \mathrm{U}$ of calparine was injected into subcutaneous tissue of five mice in each group. On day 21 , five mice in each group were treated as above-mentioned. One week later, Matrigels were harvested and washed with normal saline thrice. Then, they were kept on dry ice for $12 \mathrm{~h}$ and mixed with $0.5 \mathrm{~mL}$ of $0.01 \mathrm{~g} / \mathrm{L}$ Triton-100 followed by incubation for 1-2 h. The suspension was centrifuged at $1500 \mathrm{rpm}$ for $10 \mathrm{~min}$, and the supernatant was harvested. The sample $(20 \mu \mathrm{L})$ was dissolved in $5 \mathrm{~mL}$ of Drabkin liquid (200 $\mathrm{mg}$ of $\mathrm{K}_{3}\left[\mathrm{Fe}(\mathrm{CN})_{6}\right]$, $50 \mathrm{mg}$ of $\mathrm{KCN}, 1 \mathrm{~g}$ of $\mathrm{NaHCO}_{3}$ and $1000 \mathrm{~mL}$ of distilled water) followed by incubation for $40 \mathrm{~min}$. The spectrophotometer was used to measure the absorbance (A) at $595 \mathrm{~nm}$. The concentration of hemoglobin was calculated according to the following formula: $\mathrm{Hb}(\mathrm{g} / \mathrm{L})=\mathrm{A}$ $\times(64458 / 44000) \times 251$. The extent of angiogenesis was evaluated by the concentration of hemoglobin.

The osteosarcoma-bearing mice $(n=20)$ in TR group received left forelimb amputation to remove the tumor completely, and mice in the SO and UT groups were treated as above- 
mentioned on day 14. Two weeks later, all mice were anesthetized and the lungs were removed. Mice with macroscopic pulmonary metastasis were recorded, and the incidence of metastasis was calculated individually. Then, pulmonary tissues were fixed in 10\% formaldehyde and prepared for routine histological examination. Each experiment was performed in triplicate and found to be reproducible.

\section{Statistical analysis}

Statistical analysis was performed with SPSS 13.0 (Chicago, IL). Quantitative data were expressed as mean \pm standard deviation (SD). One-way analysis of variance was employed to compare the means among groups. The least significant difference (LSD) was used to compare the means between two groups. A value of $p<0.05$ was considered statistically significant.

\section{Results}

After operation, the expression of endostatin and VEGF in the TR group decreased significantly when compared with the other two groups (VEGF: TR: $79.55 \pm 7.82 \mathrm{pg} / \mathrm{mL}$ vs. SO: 110.01 $\pm 5.69 \mathrm{pg} / \mathrm{mL}$, UT: $123.50 \pm 10.41 \mathrm{pg} / \mathrm{mL}, p<0.01$; endostatin: $47.09 \pm 6.22 \mathrm{ng} / \mathrm{mL} v s .117 .64 \pm 7.39 \mathrm{ng} / \mathrm{mL}, 126.73 \pm 6.55 \mathrm{ng} / \mathrm{mL}$, $p<0.01$ ) (Figures 1 and 2). There was no significant difference in the expression of VEGF and endostatin between SO group and UT group on days $7,14,21$ and 28 .

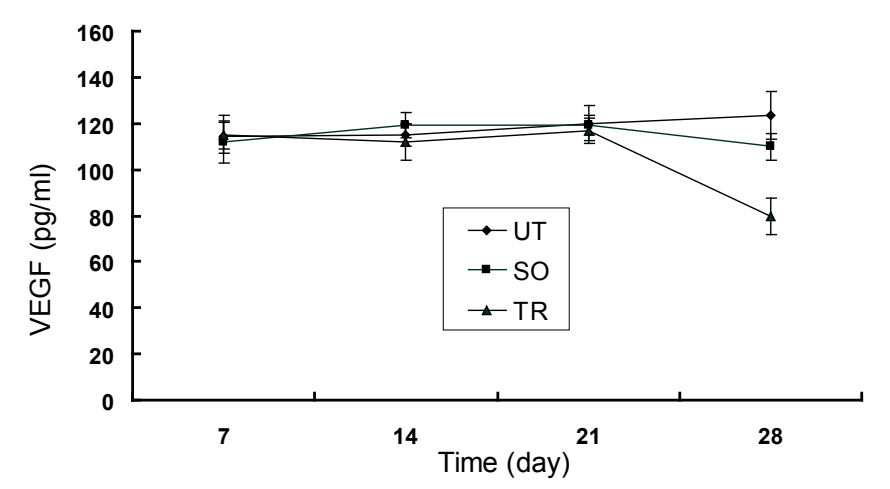

FIGURE 1 - VEGF expression in three groups. The levels of VEGF were relatively stable preoperatively and when the mice were treated non-operatively as well as by sham amputation. The level of VEGF in peripheral circulation was $110.01 \pm 5.69 \mathrm{pg} / \mathrm{mL}$ and $123.50 \pm 10.41 \mathrm{pg} /$ $\mathrm{mL}$ in the SO group and UT group, respectively, after surgery. However, it significantly decreased to $79.55 \pm 7.82 \mathrm{pg} / \mathrm{mL}$ after tumorectomy $(p<0.01)$.

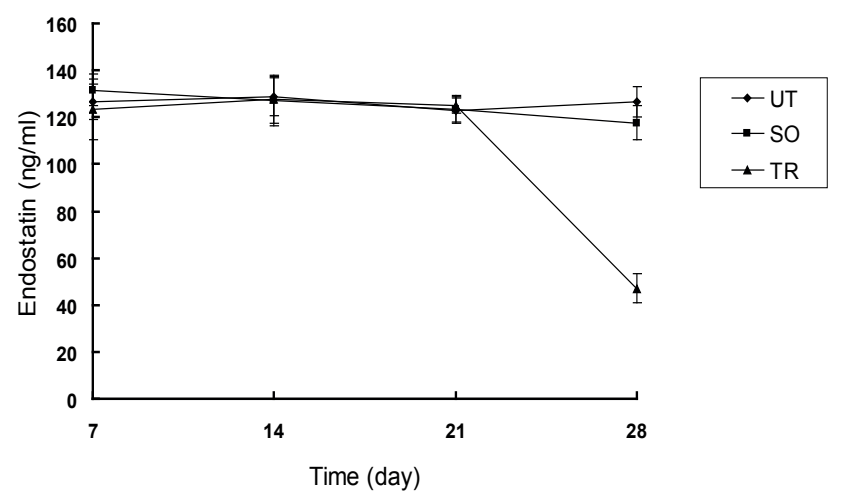

FIGURE 2 - Endostatin expression in three groups.

In the TR group, the content of hemoglobin in the Matrigel increased significantly as compared to the other two groups after surgery (TR: $38.25 \pm 4.45 \mathrm{~g} / \mathrm{L} v s$. SO: $18.71 \pm 1.33 \mathrm{~g} / \mathrm{L}$, UT: 17.90 $\pm 1.76 \mathrm{~g} / \mathrm{L} ; p<0.01$ ) (Figure 3 ). However, no significant difference in the hemoglobin content was found between SO group and UT group on days $7,14,21$ and 28 .

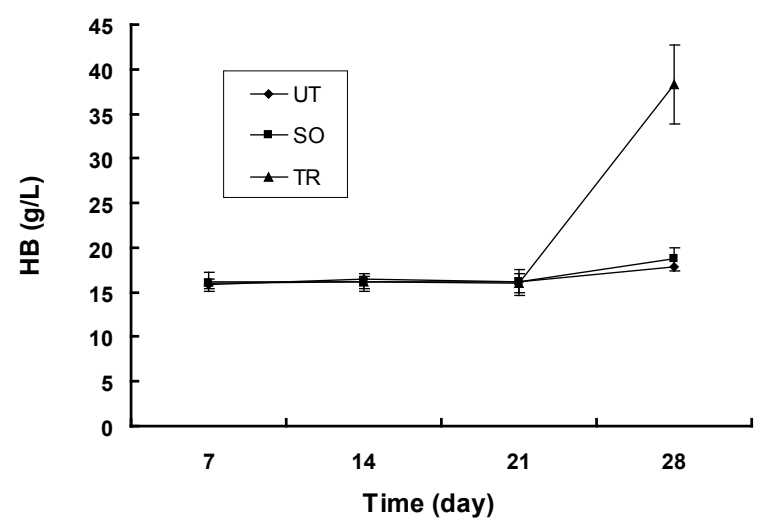

FIGURE 3 - Hemoglobin concentration in the Matrigel.

Additionally, in the TR group, 16 mice developed micrometastatic foci in the lung, which were found in only eight mice of SO group and seven mice of UT group. The incidence of pulmonary metastasis was $80.0 \%, 40.0 \%$ and $35.0 \%$ in the TR, SO and UT groups, respectively. Histologically, the severity of metastatic foci was higher in the TR group than in other two groups.

The endostatin level was relatively stable preoperatively and when the animals were treated non-operatively as well as by sham amputation. The level of endostatin in peripheral circulation was $117.64 \pm 7.39 \mathrm{ng} / \mathrm{mL}$ and $126.73 \pm 6.55 \mathrm{ng} / \mathrm{mL}$ in the $\mathrm{SO}$ group and UT group, respectively, after surgery. However, it significantly decreased to $47.09 \pm 6.22 \mathrm{ng} / \mathrm{mL}$ after tumorectomy $(p<0.01)$. 
Hemoglobin was maintained at a stable level preoperatively and when the animals were treated non-operatively or by sham amputation. The level of hemoglobin in the Matrigel was $18.71 \pm 1.33 \mathrm{~g} / \mathrm{L}$ and $17.90 \pm 1.76 \mathrm{~g} / \mathrm{L}$ in the $\mathrm{SO}$ group and UT group, respectively, after surgery. However, it markedly increased to $38.25 \pm 4.45 \mathrm{~g} / \mathrm{L}$ after tumorectomy $(p<0.01)$.

\section{Discussion}

Osteosarcoma is a highly malignant tumor that commonly affects children and young adults. Before wide application of neoadjuvant chemotherapy, approximately $80 \%$ of osteosarcoma patients develop systemic metastasis following surgical intervention. Even with multi-disciplinary treatment, more than half patients develop pulmonary metastasis, which has been a najor cause of death in patients with osteosarcoma ${ }^{6}$. Thus, it is imperative to develop measurements to diagnose and prevent pulmonary metastasis. Previous studies have showed that pulmonary metastasis of osteosarcoma is associated with the progression and termination of primary cancer. Kaya et al. ${ }^{12}$ found that the removal of primary cancer could promote the progression of pulmonary metastasis of osteosarcoma. Such relationship between primary tumorectomy and metastasis has also been found in other solid tumors ${ }^{13-17}$. Li et $a l .{ }^{13}$ investigated the influence of tumorectomy on cancer growth in a cancer-bearing mouse model. They found that primary tumorectomy could accelerate the growth of pre-existing metastatic cancers which was probably related to multiple factors such as increases in angiogenesis and cancer cell proliferation and decrease in cancer cell apoptosis. Streck et al. ${ }^{14}$ compared the growth of metastatic liver cancer arising spontaneously from a subcutaneous cancer in mice, and results showed that the weight of metastatic liver cancer was significantly lower in mice without tumorectomy than in those undergoing primary tumorectomy. Compared with the rapid progression of micrometastatic cancer after primary tumorectomy, metastatic cancer always grow slowly provided that primary cancer is left intact. This distinct phenomenon that primary cancer is able to inhibit the growth of micrometastasis is known as CTR ${ }^{9}$.

The exact mechanism of CTR is not well defined; however, there are several hypotheses to explain this unique phenomenon. Bashford et al. ${ }^{18}$ assumed that CTR was induced by immune reaction and called it "concomitant immunity". Several years later, investigators also identified this phenomenon in non-detectable immunogenicity or immunodeficient mice with cancer, and the term "concomitant immunity" was deserted ${ }^{10,19}$. Prehn ${ }^{10}$ suggested that concomitant resistance could be reasonably explained by the competence of two co-existing cancers. Other hypotheses include nutrient deprivation and anti-mitogens secreted by primary cancers ${ }^{7}$. However, none of above-mentioned hypotheses can explain the molecular biology of concomitant resistance. Recently, some researchers propose that CTR is related to the angiogenic factors secreted by primary cancer ${ }^{20,21}$. Scharovsky et al. ${ }^{15}$ found that CTR was associated with the ratio of angiogenic factors/anti-angiogenic factors. Kaya et al. ${ }^{12}$ found the level of endostatin, an important antiangiogenic factor, decreased significantly after primary resection of osteosarcoma. In the present study, our results also revealed that the levels of VEGF and endostatin decreased dramatically after primary tumorectomy, which was coincident with previously reported.

VEGF and endostatin are both factors secreted by primary cancer and have different half-lives in the serum. The half-life of VEGF is relatively short, and the VEGF level decreases rapidly in the peripheral circulation. However, the half-life of endostatin is much longer and the endostatin can be maintained at a relatively stable level when the primary cancer is kept intact. As a result, a special antiangiogenic circumstance develops accordingly in the internal environment and micrometastasis is restricted from invading and growing. However, the levels of VEGF and endostatin decrease rapidly after primary tumorectomy, and thus the antiangiogenic environment disappears. The hypothesis is that the metastatic tumors may replace the primary tumor and exert antiangiogenetic effect. Undoubtedly, the efficacy could not help it to regain previous powerful steps and gradual pulmonary metastasis has been made on the agenda. Interestingly, Jia et al. ${ }^{22}$ found that the $\mathrm{VEGF}_{165}$ was necessary for the metastatic potential of Fas ${ }^{-}$osteosarcoma cells but unrelated to the metastasis of $\mathrm{Fas}^{+}$ cells. $\mathrm{VEGF}_{165}$ expression decreased in $\mathrm{LM} / \mathrm{siRNA}_{165}$ cells and increased in LM7/VEGF clones, while Fas was not correlated with these transfected clones. $\mathrm{VEGF}_{165}$ is the strongest stimulator ofr angiogenesis, and the crosstalk of VEGF with other factors is required to be investigated further aiming to elucidate the molecular mechanism of spontaneous metastasis.

Based on our findings, we may speculate that it is necessary to consider additional antiangiogenic treatment after primary tumorectomy. The anti-angiogenic therapy represents a new approach to cure osteosarcoma and has several advantages as compared to traditional adjuvant chemotherapy. The antiangiogenic therapy can inhibit the cancer growth through interrupting angiogenesis in cancers, and it is more selective and efficient than conventional chemotherapy. Meanwhile, the novel treatment may reduce the incidence of drug resistance because the target of angiogenic inhibitors is vascular endothelial cells 
which are genetically stable. It is supposed that favorable outcome might be achieved when anti-angiogenic treatment is applied in combination with neoadjuvant chemotherapy ${ }^{23}$. Kaya et al. ${ }^{8}$ found that the angiogenic inhibitor (endostatin) could suppress the pulmonary metastasis of osteosarcoma after primary tumorectomy. The anti-angiogenic therapy has clinical significance in preventing pulmonary metastasis of osteosarcoma after primary tumorectomy 24-26.

\section{References}

1. Longhi A, Errani C, De Paolis M, Mercuri M, Bacci G. Primary bone osteosarcoma in the pediatric age: state of the art. Cancer Treat Rev. 2006;32:423-36.

2. Tomoda R, Seto M, Hioki Y, Sonosa J, Matsumine A, Kusuzaki K, Uchida A. Low-dose methotrexate inhibits lung metastasis and lengthens survival in rat osteosarcoma. Clin Exp Metastasis. 2005;22:559-64.

3. Cao Y, O'Reilly MS, Marshall B, Flynn E, Ji RW, Folkman J. Expression of angiostatin cDNA in a murine fibrosarcoma suppresses primary tumor growth and produces long-term dormancy of metastases. J Clin Invest. 1998;101:1055-63.

4. Pakos EE, Nearchou AD, Grimer RJ, Koumoullis HD, Abudu A, Bramer JA, Jeys LM, Franchi A, Scoccianti G, Campanacci D, Capanna R, Aparicio J, Tabone MD, Holzer G, Abdolvahab F, Funovics P, Dominkus M, Ilhan I, Berrak SG, Patino-Garcia A, Sierrasesumaga L, San-Julian M, Garraus M, Petrilli AS, Filho RJ, Macedo CR, Alves MT, Seiwerth S, Nagarajan R, Cripe TP, Ioannidis JP. Prognostic factors and outcomes for osteosarcoma: an international collaboration. Eur J Cancer. 2009; 45:2367-75.

5. Snyder CL, Saltzman DA, Ferrell KL, Thompson RC, Leonard AS. A new approach to the resection of pulmonary osteosarcoma metastases. Results of aggressive metastasectomy. Clin Orthop Relat Res. 1991;270:247-53.

6. Quan GM, Choong PF. Anti-angiogenic therapy for osteosarcoma. Cancer Metastasis Rev. 2006;25:707-13.

7. Tsunemi T, Nagoya S, Kaya M, Kawaguchi S, Wada T, Yamashita T, Ishii S. Postoperative progression of pulmonary metastasis in osteosarcoma. Clin Orthop Relat Res. 2003;407:159-66.

8. Kaya M, Wada T, Nagoya S, Yamashita T. Prevention of postoperative progression of pulmonary metastases in osteosarcoma by antiangiogenic therapy using endostatin. J Orthop Sci. 2007;12:562-7.

9. Prehn RT. The inhibition of tumor growth by tumor mass. Cancer Res. 1991;51:2-4.

10. Prehn RT. Two competing influences that may explain concomitant tumor resistance. Cancer Res. 1993;53:3266-9.

11. Mei J, Ni M, Chen YX, Yao B, Gao YS, Yu XM, Wang ZY. Effects of primary tumor excision on angiogenesis and pulmonary metastasis in osteosarcoma-bearing nude mice. Zhonghua Zhong Liu Za Zhi. 2009;31:246-9.

12. Kaya M, Wada T, Nagoya S, Kawaguchi S, Isu K, Yamashita T. Concomitant tumour resistance in patients with osteosarcoma. A clue to a new therapeutic strategy. J Bone Joint Surg Br. 2004;86:143-7.

13. Li TS, Kaneda Y, Ueda K, Hamano K, Zempo N, Esato K. The influence of tumour resection on angiostatin levels and tumour growth-an experimental study in tumour-bearing mice. Eur J Cancer. 2001;37:2283-8.

14. Streck C, Zhang Y, Zhou J, Ng CY, Davidoff A. Endostatinmediated concomitant resistance in neuroblastoma. J Pediatr Surg.
2004;39:405-11

15. Scharovsky OG, Binda MM, Rozados VR, Bhagat VR, Cher ML, Bonfil RD. Angiogenic and antiangiogenic balance regulates concomitant antitumoral resistance. Clin Exp Metastasis. 2004;21:177-83.

16. Binda MM, Matar P, González AD, Rozados VR, Gervasoni SI, Scharovsky OG, Bonfil RD. Differential production of angiostatin by concomitant antitumoral resistance-inducing cancer cells. Int $\mathrm{J}$ Cancer. 2002;100:14-21.

17. Kisker O, Onizuka S, Banyard J, Komiyama T, Becker CM, Achilles EG, Barnes CM, O'Reilly MS, Folkman J, Pirie-Shepherd SR. Generation of multiple angiogenesis inhibitors by human pancreatic cancer. Cancer Res. 2001;61:7298-304.

18. Bashford E, Murry JA, Cramer W. The natural and induced resistance of mice to the growth of cancer. Proc R Soc London. 1907;79:16487.

19. Michelson S, Leith JT. A theoretical explanation of "concomitant resistance". Bull Math Biol. 1995;57:733-47.

20. Sacco MG, Caniatti M, Catò EM, Frattini A, Chiesa G, Ceruti R, Adorni F, Zecca L, Scanziani E, Vezzoni P. Liposome-delivered angiostatin strongly inhibits tumor growth and metastatization in a transgenic model of spontaneous breast cancer. Cancer Res. 2000;60:2660-5.

21. Volpert OV, Lawler J, Bouck NP. A human fibrosarcoma inhibits systemic angiogenesis and the growth of experimental metastases via thrombospondin-1. Proc Natl Acad Sci USA. 1998;95:6343-8.

22. Jia SF, Guan H, Duan XP, Kleinerman ES. VEGF165 is necessary to the metastatic potential of Fas- osteosarcoma cell but will not rescue the Fas+ cells. J Exp Ther Oncol. 2008;7:89-97.

23. Kerbel RS. Tumor angiogenesis. N Engl J Med. 2008;358:2039-49.

24. Gao YS, Mei J, Tong TL, Hu M, Xue HM, Cai XS. Inhibitory effects of VEGF-siRNA mediated by adenovirus on osteosarcoma-bearing nude mice. Cancer Biother Radiopharm. 2009;24:243-7.

25. Mei J, Gao Y, Zhang L, Cai X, Qian Z, Huang H, Huang W. VEGFsiRNA silencing induces apoptosis, inhibits proliferation and suppresses vasculogenic mimicry in osteosarcoma in vitro. Exp Oncol. 2008;30:29-34.

26. Wang JQ, Gao YS, Mei J, Xue HM, Wang SQ, Cai XS. Morphological changes in osteosarcoma xenografts in nude mice after inhibiting angiogenesis by Ad-VEGF-siRNA. Ai Zheng. 2009;28:581-6.

\section{Correspondence:}

Jiong Mei

Department of Orthopedic Surgery, Tongji Hospital

Tongji University, No. 389 Xincun Road

Shanghai 200065, China

Phone: +86-1891-7233480

Mobile: $+86-1390-1870631$

Fax: +86-21-56050502

drmeijiong@126.com

Received: October 15, 2012

Review: December 17, 2012

Accepted: January 18, 2013

Conflict of interest: none

Finance source: National Natural Science Foundation of China

${ }^{1}$ Research performed at Tongji University, School of Medicine, Shanghai, China. 